\title{
Article \\ Cathepsin B Localizes in the Caveolae and Participates in the Proteolytic Cascade in Trabecular Meshwork Cells. Potential New Drug Target for the Treatment of Glaucoma
}

\author{
April Nettesheim ${ }^{1,+}$, Myoung Sup Shim ${ }^{1,+}{ }^{\oplus}$, Angela Dixon ${ }^{1}$, Urmimala Raychaudhuri ${ }^{1}$, Haiyan Gong ${ }^{2}$ and \\ Paloma B. Liton 1 * \\ 1 Department of Ophthalmology \& Pathology, Duke University, Durham, NC 27705, USA; \\ april.nettesheim@duke.edu (A.N.); myoungsup.sim@duke.edu (M.S.S.); angela.norman@duke.edu (A.D.); \\ urmimala.raychaudhuri@duke.edu (U.R.) \\ 2 Department of Ophthalmology, Boston University School of Medicine, Boston, MA 02118, USA; \\ hgong@bu.edu \\ * Correspondence: paloma.liton@duke.edu; Tel.: +1-919-681-4085 \\ + Co-first authorship.
}

Citation: Nettesheim, A.; Shim, M.S.; Dixon, A.; Raychaudhuri, U.; Gong, H.; Liton, P.B. Cathepsin B Localizes in the Caveolae and Participates in the Proteolytic Cascade in Trabecular Meshwork Cells. Potential New Drug Target for the Treatment of Glaucoma. J. Clin. Med. 2021, 10, 78. https://doi. org $/ 10.3390 /$ jcm10010078

Received: 25 November 2020 Accepted: 24 December 2020 Published: 28 December 2020

Publisher's Note: MDPI stays neutral with regard to jurisdictional claims in published maps and institutional affiliations.

Copyright: $\odot 2020$ by the authors. Licensee MDPI, Basel, Switzerland. This article is an open access article distributed under the terms and conditions of the Creative Commons Attribution (CC BY) license (https: / / creativecommons.org / licenses/by/4.0/).

\begin{abstract}
Extracellular matrix (ECM) deposition in the trabecular meshwork (TM) is one of the hallmarks of glaucoma, a group of human diseases and leading cause of permanent blindness. The molecular mechanisms underlying ECM deposition in the glaucomatous TM are not known, but it is presumed to be a consequence of excessive synthesis of ECM components, decreased proteolytic degradation, or both. Targeting ECM deposition might represent a therapeutic approach to restore outflow facility in glaucoma. Previous work conducted in our laboratory identified the lysosomal enzyme cathepsin B (CTSB) to be expressed on the cellular surface and to be secreted into the culture media in trabecular meshwork (TM) cells. Here, we further investigated the role of CTSB on ECM remodeling and outflow physiology in vitro and in CSTB ${ }^{\mathrm{ko}}$ mice. Our results indicate that CTSB localizes in the caveolae and participates in the pericellular degradation of ECM in TM cells. We also report here a novel role of CTSB in regulating the expression of PAI-1 and $\mathrm{TGF} \beta /$ Smad signaling in TM cells vitro and in vivo in $\mathrm{CTSB}^{\mathrm{ko}}$ mice. We propose enhancing CTSB activity as a novel therapeutic target to attenuate fibrosis and ECM deposition in the glaucomatous outflow pathway.
\end{abstract}

Keywords: glaucoma; trabecular meshwork; cathepsin B; fibrosis; TGF $\beta$; ECM; PAI-1; proteolytic cascade

\section{Introduction}

The trabecular meshwork (TM) is a tissue located in the anterior segment of the eye, which has a major role in regulating intraocular pressure (IOP), by controlling the resistance to aqueous humor $(\mathrm{AH})$ outflow from the eye. Functional failure of the TM causes ocular hypertension and predisposes the development of primary open angle glaucoma (POAG), a group of eye diseases leading cause of permanent blindness worldwide [1,2].

The TM consists of sheets of connective tissue beams through which AH must flow before exiting the eye. Each beam is composed of a central elastic core surrounded by collagen fibers embedded in a ground substance, lined by TM endothelial cells. With aging and in disease, the trabecular beams become thicker due to thickening of the basement membrane underlying the trabecular cells or changes in the extracellular matrix (ECM) within the central core. In the TM of glaucomatous eyes, deposition of long-spacing collagen is also frequently observed [3]. The exact causes responsible for this thickening of the beams and deposit of ECM remain unknown, but are likely due to excessive ECM synthesis, decreased proteolytic degradation, or both [4]. Excessive synthesis possibly plays a role because the aqueous humor $(\mathrm{AH})$ of patients with POAG contains elevated 
concentrations of TGF- $\beta 2[5,6]$, a cytokine that promotes ECM deposition and increases outflow resistance [6,7]. Degradation is controlled extracellularly by the action of proteases. Regulation of the ECM composition in the TM is known to play a major role in both outflow pathway physiology and pathophysiology $[4,8,9]$; however, the exact mechanisms underlying ECM remodeling with IOP changes and those associated with its alteration in glaucoma remain poorly understood [10].

Despite the general belief that matrix metalloproteinases (MMPs) are the only group of enzymes responsible for ECM degradation, emerging evidence in other tissues suggests that other proteases or the coordinated action of several types of proteases, other than just MMPs, participate in bulk matrix degradation and ECM remodeling [11]. In this line, previous studies conducted in our laboratory reported for the first time a role of the lysosomal cysteine protease cathepsin B (CTSB) in intracellular degradation of ECM components in TM cells [12]. We found partially degraded ECM products associated with active CTSB in lysosomal compartments. Moreover, CTSB was found to be constitutively expressed in the cell surface and secreted to the culture media in its inactive pro-form. CTSB was also detected in AH samples. Surface expression and secretion of cathepsins are not unique to TM cells. Although preferentially located in lysosomes, specific subtypes of cathepsins (CTSB, CTSL, CTSK, CTSD) have been located on the cell surface as well as secreted into the extracellular space in different cell types, preferentially of mesenchymal origin, either constitutively or under stress conditions [13-15]. In particular, surface CTSB has been localized in caveolae in HUVEC endothelial and colorectal carcinoma cells $[16,17]$. Caveolae are lipid-rich invaginations of the plasma that play a key role in regulating cell signaling, lipid homeostasis, and adaptation to membrane tension. Emerging studies are now showing that caveolae are also important regulators of ECM remodeling, acting as focal proteolytic degradation sites. CTSB activity at the cellular membrane has been associated with the pericellular degradation of ECM and basement membrane proteins and contribute to cell migration in cancer cells $[15,17,18]$. Interestingly, CTSB has been also shown to promote epithelial-mesenchymal transition (EMT) in tumor cells and contribute to tissue fibrosis [19].

Given the relevance of fibrosis and EMT transition in outflow pathway pathophysiology, we decided to follow up on our initial observations and to further investigate a role of CTSB in ECM remodeling and TM tissue function. Here, we show for the first time that surface CTSB localizes in the caveolae and participates in the pericellular proteolytic cascade in TM cells and TGF $\beta$ signaling.

\section{Experimental Section}

\subsection{Cell Culture}

Primary human TM cells were isolated from dissected TM tissue from discarded corneal rims after surgical corneal transplantation at Duke University Eye Center and maintained as described earlier [20]. Cells were passaged when confluent at a 1:2 ratio. Cells from passage 4-8 were used in this study. HTM cells were characterized by morphology and by the upregulation of myocilin in response to dexamethasone treatment, in accordance to the consensus recommendations for TM cell isolation, characterization, and culture [21]. The protocols involving the use of human tissue were consistent with the tenets of the Declaration of Helsinki.

\subsection{Preparation of Caveolae-Enriched Fractions}

Caveolae-enriched fractions were prepared using the Caveolae Isolation Kit (SigmaAldrich, St. Louis, MO, USA) following the manufacturer's instruction. This kit is based on the resistance of caveolae to solubilization in ice cold Triton X-100. Briefly, one confluent $100 \mathrm{~mm}$-tissue culture dish of hTM cells was washed twice with cold $1 \times$ PBS and lysed on ice in proprietary Lysis Buffer containing $1 \%$ Triton X-100. Fractions were fractionated by OptiPrep density gradient ultracentrifugation and collected in $1 \mathrm{~mL}$ fractions. Caveolin-1 (Cav1) was used as a marker for caveolae-enriched fractions (fractions 2-5). 


\section{3. siRNA Transfection}

Human primary TM cells were transfected with siCTSB ( 25 pmol, Santa Cruz Biotechnology, Dallas, TX, USA; sc-29238) using Lipofectamine RNAiMAX protocol (Invitrogen) following the manufacturer's instructions. A non-targeting siRNA (siNC) was used as control.

\subsection{Whole-Cell and Tissue Lysates Preparation}

Cells and dissected iridocorneal region tissue were washed twice in PBS and lysed for 30 min in RIPA buffer (Millipore Sigma, Burlington, MA, USA; R0278) containing 1:100 Halt protease and phosphatase inhibitor cocktail (Thermo Scientific, Waltham, MA, USA; 78842). After sonication for one minute on ice, lysates were clarified by centrifugation. Protein concentration was determined using a protein assay kit (Micro BCA, Thermo Scientific, Waltham, MA, USA; 23235).

\subsection{Western Blot Analysis}

For WB analysis, proteins $(2.5-10 \mu \mathrm{g})$, cell culture medium $(3.5-20 \mu \mathrm{L})$, or caveolaenriched fractions $(15 \mu \mathrm{L})$ were separated by SDS-PAGE (10-15\%) and transferred to PVDF membrane (Bio-Rad). Membranes were blocked with 5\% non-fat dry milk in PBS-T $(0.1 \%$ Tween-20) for $1 \mathrm{~h}$ at room temperature or overnight at $4{ }^{\circ} \mathrm{C}$ and incubated with primary antibodies diluted in blocking buffer overnight at $4{ }^{\circ} \mathrm{C}$. Membranes were washed three times with PBS-T and incubated with peroxidase-conjugated secondary antibodies for 1-2 $\mathrm{h}$ at room temperature. Bands were detected using chemiluminescence substrate (HyGlo Quick Spray, Denville, Swedesboro, NJ, USA; E2400). Blots were scanned using ChemiDoc Image System and analyzed by densitometry using Image J. ACTB or GAPDH were used for normalization. Primary antibodies and dilutions used in the study are listed in Table 1.

Table 1. List of antibodies and dilutions.

\begin{tabular}{cccc}
\hline Protein & Company & Catalog & Dilution \\
\hline CTSB & Cell Signaling & $31718 S$ & $1: 1000$ \\
Cav1 & Sigma & C3237 & $1: 1000$ \\
Annexin & Santa Cruz Biotechnology & Sc-28385 & $1: 1000$ \\
uPA & R\&D & MAB9185 & $1: 1000$ \\
uPAR & R\&D & MAB807 & $1: 1000$ \\
PAI-1 & Santa Cruz Biotechnology & Sc-47724 & $1: 250$ \\
GAPDH & Santa Cruz Biotechnology & ABC20 & $1: 500$ \\
CSTC & Millipore & A2547 & $1: 1000$ \\
SMA & Sigma & $31718 S$ & $1: 1000$ \\
FN1 & Santa Cruz Biotechnology & Sc-69879 & $1: 2000$ \\
ACTB & Santa Cruz Biotechnology & $1: 500$ \\
\hline
\end{tabular}

\subsection{RNA Isolation and Quantitative Real-Time PCR}

Total RNA was isolated from human TM cells using RNeasy kit (Qiagen) according to the manufacturer's protocol and treated in-column with DNase I (Qiagen). RNA yields were measured using Nanodrop spectrophotometry (NanoDrop 1000, Thermo Scientific, Waltham, MA, USA). First-strand cDNA was synthesized from total RNA $(1 \mu \mathrm{g})$ by reverse transcription using oligo(dT) primer and reverse transcriptase (SuperScript First Strand System, Thermo Scientific, Waltham, MA, USA). Real-time PCR was performed in a $20 \mu \mathrm{L}$ mixture containing $1 \mu \mathrm{L}$ of the cDNA preparation diluted five times, $10 \mu \mathrm{L}$ master mix (SsoFast EvaGreen Supermix, Bio-Rad, Hercules, CA, USA), and $500 \mathrm{~nm}$ of each primer in a thermocycler system (iCycler iQ; Bio-Rad, Hercules, CA, USA) using the following PCR parameters: $95{ }^{\circ} \mathrm{C}$ for $5 \mathrm{~min}$, followed by 50 cycles of $95{ }^{\circ} \mathrm{C}$ for $15 \mathrm{~s}, 60{ }^{\circ} \mathrm{C}$ for $15 \mathrm{~s}$, and $72{ }^{\circ} \mathrm{C}$ for $15 \mathrm{~s}$. The fluorescence threshold value $(\mathrm{Ct})$ was calculated using the thermocycler system software. The absence of nonspecific products was confirmed by both the analysis of the melt curves and by electrophoresis in 3\% acryl-agarose gels. $\beta$-Actin 
and GAPDH served as an internal standard of mRNA expression. The change ( $\mathrm{x}$-fold) was calculated with the formula $2^{-\Delta \Delta \mathrm{Ct}}$, where $\Delta \mathrm{Ct}=\mathrm{Ct}_{\text {gene }}-\mathrm{Ct}_{\mathrm{Act}}$, and $\Delta \Delta \mathrm{Ct}=\Delta \mathrm{Ct}_{\mathrm{Exp}}-$ $\Delta \mathrm{Ct}_{\mathrm{Con}}$. The sequences of the primers used for the amplifications are: PAI-1: TGF TGG TGA ATG CCC TCT ACT and CGG TCA TTC CCA GGT TCT CTA.

\subsection{In Situ Zymography}

Live cell proteolysis was assayed as previously described [12], with some modifications. Briefly, 24-well plates were coated with $50 \mu \mathrm{L}$ of 1.5\% (w/v) gelatin (Sigma, G1393) containing $25 \mu \mathrm{g} / \mathrm{mL}$ DQ-gelatin or DQ-Collagen I (Thermo Fisher Scientific, Waltham, MA, USA; D12054) and incubated on ice for $15 \mathrm{~min}$ to solidify. Cells $\left(2.5 \times 10^{4}\right)$ were seeded onto coated wells and incubated at $5 \% \mathrm{CO}_{2}, 37^{\circ} \mathrm{C}$, for $48 \mathrm{~h}$. CA074Me $(40 \mu \mathrm{M}$; Enzo life science, Farmingdale, NY, USA; BML- PI 126), E-64d (10 $\mu \mathrm{M}$; Sigma-Aldrich, St. Louis, MO, USA; E8640) or marimastat (10 $\mu \mathrm{M}$; Sigma-Aldrich, St. Louis, MO, USA; M2699) were added to the culture media to inhibit CTSB, cysteine cathepsins, or MMP activities, respectively. Fluorescence peptides released by the enzymatic cleavage of the substrate at the pericellular region was observed in live cells using the CELENA ${ }^{\circledR}$ X High Content Imaging System (Logos biosystems, Annandale, VA, USA) coupled with a stage top incubation system (Ibidi USA, Inc., Fitchburg, WI, USA). Nuclei were stained by $15 \mathrm{~min}$ incubation with Hoechst 33342. Intracellular proteolysis of internalized DQ-substrates was quantified by flow cytometry in FL1 channel.

\subsection{Mechanical Stretch}

Cyclic mechanical stretch (CMS, $8 \%$ elongation, $1 \mathrm{~Hz}$ ) was applied using the Flexcell ${ }^{\circledR}$ FX-5000 ${ }^{\mathrm{TM}}$ Tension System (Flexcell International Corp, Burlington, NC, USA), as described previously [22].

\subsection{ELISA}

Secreted TGF $\beta 1$ and TGF $\beta 2$ were measured by ELISA (Invitrogen, BMS249-4 and BMS254, respectively) in $100 \mu \mathrm{L}$ of clarified culture media, according to the manufacturer's protocol.

\subsection{CTSB $^{k o}$ Mice}

$\mathrm{CTSB}^{\mathrm{ko}}$ mice were obtained from Dr. Henriette Van Praag at Florida Atlantic University (Boca Raton, FL, USA) [23]. Generation of these mice has been described in [24]. Mice were maintained and aged in situ. Genotyping was performed by PCR in digested tail genomic DNA using the following primers with a temperature annealing of $57.5^{\circ} \mathrm{C}$ for $45 \mathrm{~s}$ (F: GGT TGC GTT CGC TGA GG; R: AAC AAG AGC CGC AGG AGC). CTSB ${ }^{\mathrm{ko}}$ and littermates CTSB wild-type (males and females) were used for experimental purposes. Animals were maintained under a $12 \mathrm{~h}$ light/dark cycle, fed a standard mouse diet, and provided with water ad libitum. Animal euthanasia was performed via $\mathrm{CO}_{2}$ asphyxiation, followed by bilateral thoracotomy, prior to immediate enucleation. Enucleated eyes destined for electron microscopy (EM) were fixed under perfusion in $2 \%$ glutaraldehyde $/ 0.1 \mathrm{M}$ cacodylate buffer. Tissues destined for WB analysis were immediately dissected and flash frozen on dry ice. All procedures were reviewed and approved by the Institutional Animal Care and Use Committee of Duke University and were performed in accordance with the ARVO Statement for the Use of Animals in Ophthalmic and Vision Research and the National Institutes of Health Guide for the Care and Use of Laboratory Animals.

\subsection{IOP Measurements}

IOP was measured between 10 a.m. and 12 p.m., bi-monthly in isoflurane-anesthetized mice using a TonoLab rebound tonometer (Colonial Medical Supply, Franconia, NH, USA). Six measurements, taken within $5 \mathrm{~min}$ after anesthesia, were collected per eye and averaged to obtain a single IOP value per eye for each session. 


\subsection{Ex-Vivo Outflow Facility}

Eyes were enucleated within $5 \mathrm{~min}$ of death and kept in a warmed solution of $5.5 \mathrm{mM}$ glucose in Dulbecco's PBS with calcium and magnesium (DBG) until perfusion (15-20 min). Outflow facility measurements were conducted ex-vivo using the iPerfusion MK V system [25]. For this, eye cups were affixed with a small amount of cyanoacrylate glue (Locktite, Henkel Corporation, Rocky Hill, CT, USA) to platforms within heated baths filled with DBG. XYZ micromanipulators (World Precision Instruments, Sarasota, FL, USA) were used to cannulate the anterior chamber of each eye with a glass microneedle. The glass microneedles were manufactured in-house by pulling glass capillary tubes (PN-3 Puller, Narishge Scientific Instrument Lab, Tokyo, Japan) and sharpened to a 20 degree bevel (BV-10, Sutter Instrument Company, Novato, CA, USA). An initial pressure of $8 \mathrm{mmHg}$ for a period of $30 \mathrm{~min}$ was applied to allow acclimatization of the eyes to pressure and temperature environment. A nine-step post acclimatization protocol was conducted with applied pressures of 5.0, 6.5, 8.0, 9.5, 11.0, 12.5, 14.0, 15.5, and $17.0 \mathrm{mmHg}$ before returning to $8.0 \mathrm{mmHg}$. Outflow facility was calculated with the iPerfusion integrated software [25].

\subsection{Electron Microscopy (EM)}

Enucleated eyes were post-fixed for $24 \mathrm{~h}$ in $2 \%$ glutaraldehyde $/ 0.1 \mathrm{M}$ cacodylate buffer solution and transferred to cold $3 \%$ glutaraldehyde/0.1 M cacodylate buffer for $2 \mathrm{~h}$. Eyes were then washed in cacodylate buffer, post-fixed in $2 \% \mathrm{OsO} 4 / 0.1 \mathrm{M}$ cacodylate, and dehydrated though increasing ethanol gradient ending in two cycles of propylene oxide. Tissue was infiltrated by immersion in a 1:1 mixture of propylene oxide and Epon 812 resin under a vacuum for $4-10 \mathrm{~h}$. Labeled molds were then heated at $68{ }^{\circ} \mathrm{F}$ for $8-10 \mathrm{~h}$. Sections were cut at $65 \mathrm{~nm}$ thick using a Leica EM CU7 and contrast stained with $2 \%$ uranyl acetate $/ 4 \%$ lead citrate solution. Ultrathin sections were visualized on a JEM-1400 transmission electron microscope (JEOL) using an ORIUS (1000) CCD camera. Electron microscopic images of trabecular meshwork at lower magnification (X3000-4000), and higher magnification (X10000-12000) from four wide-type and three CTSB KO mouse eyes were analyzed and compared.

\subsection{Statistical Analysis}

All in vitro experimental procedures were repeated at least three times in independent experiments with hTM primary cultures from different donors. Animal studies were conducted with $n=4$ to 11 , as indicated for each particular experiment. Data were presented as the mean \pm S.D. Statistical analysis was done in GraphPad Prism software using Student's $t$-test or 2-way ANOVA with Tukey post-test for multiple comparisons. $p<0.05$ was considered to be statistically significant.

\section{Results}

3.1. Cathepsin B Localizes in Caveolae with Components of the Proteolytic Cascade and Is Secreted into the Culture Media in Primary Cultures of TM Cells

Our laboratory previously reported that CTSB is constitutively expressed at the cell surface in porcine TM cells and secreted into the culture media in its inactive pro-CTSB form [12]. We want to investigate whether membrane CTSB localizes to caveolae, as described in HUVEC endothelial and human colorectal carcinoma cells [16,17]. For this, we purified caveolae-enriched fractions from primary human TM cultures and evaluated CTSB expression in the collected protein fractions by WB. We first analyzed the expression of the caveolae marker, caveolin 1 (CAV1). As seen in Figure 1A, CAV1 was mostly found in the low-density fractions 2 through 5 , hereafter designated as caveolae fractions, with a sharp decreased in high-density fraction 6 . Excitingly, pro-CTSB and active single-chain CTSB (scCTSB) were detected in the caveolae-enriched fractions $4-5$ and 5 , respectively. It should be noted that double-chain CTSB (dcCTSB) was found in whole-cell lysates (CL) and fraction 6, but it was not localized in the caveolae-enriched fractions. scCTSB to dcCTSB transition occurs in the lysosomes; therefore, its expression is not anticipated in 
the caveolae. It should also be noted that the caveolae purification method is based on the unique resistance of caveolae to solubilization in ice-cold Triton X-100. While caveolae do not solubilize, endosomes and lysosomes (potential contaminants) do [26]. We additionally investigated the presence in the caveolae of components of the proteolytic cascade urokinase plasminogen activator ( $\mathrm{uPA})$, its receptor ( $\mathrm{uPAR})$, and that of annexin A2 (ANXA2), a proposed binding partner of CTSB and the cell membrane. As observed in Figure 1B, all of them (uPA, uPAR and ANXA2) were identified in the caveolae-enriched fractions. A band of $\sim 55 \mathrm{kDa}$ immunoreacting with anti-uPA antibody, referred in the literature as uPA bound to plasminogen activator inhibitor type-1 (PAI-1), its natural inhibitor, was also identified. We next confirmed whether, as we previously reported in porcine TM cells, CTSB was secreted by human TM cells. For this, we analyzed CTSB expression in conditioned media from cultured human TM cells; uPA was used as control. Similar to our previous findings, pro-CTSB, but not active CTSB, was detected (Figure 1C). Altogether, these data strongly indicate that CTSB localizes in the caveolae, together with components of the proteolytic cascade, and it is secreted into the culture media in primary cultures of human TM cells.
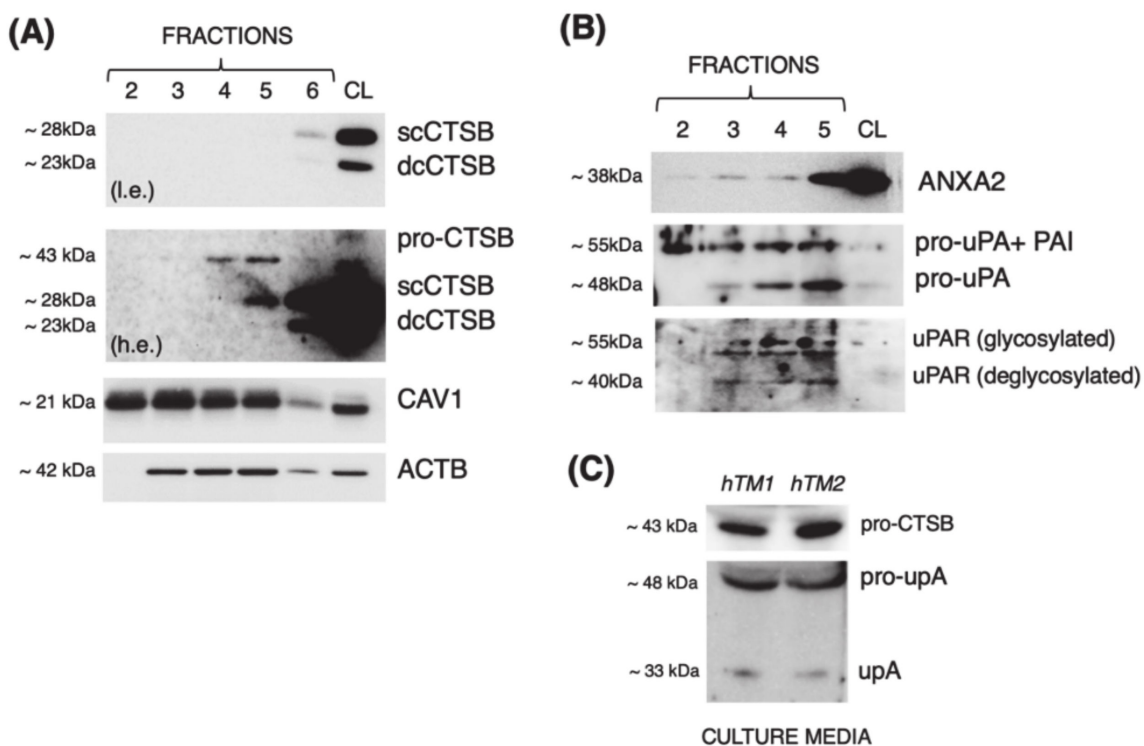

Figure 1. Localization of CTSB and members of the proteolytic cascade in the caveolae. Representative WB showing expression of (A) CTSB (pro-CTSB, sc-CTSB, dc-CTSB) and CAV1, or (B) ANXA2, prouPA and uPAR in caveolae-enriched fractions $(2-5,15 \mu \mathrm{L})$ and cell lysates (CL) from hTM cells. 1.e.: lower exposure; h.e.: higher exposure. (C) Representative WB showing expression of pro-CTSB, pro-uPA, and uPA in conditioned media $(15 \mu \mathrm{L})$ from hTM cells.

\subsection{Cathepsin B Mediates Pericellular Proteolysis of ECM in TM Cells}

The finding that CTSB localizes in caveolae with other members of the proteolytic cascade opens the question of whether CTSB participates in the pericellular degradation of ECM at the cell surface. This was investigated by in situ live zymography using DQ-gelatin, a highly quenched fluorescein-labeled gelatin that becomes fluorescence upon proteolytic digestion. Human TM cells were grown onto gelatin containing DQ-gelatin $(25 \mu \mathrm{g} / \mathrm{mL})$. Proteolytic degradation of DQ-gelatin was monitored using the Celena X imaging system. Degradation products of DQ-gelatin were observed at the cellular periphery after $48 \mathrm{~h}$ of culture (Figure 2A, green fluorescence, red arrows). We next repeated the experiment in the presence of the CTSB or the cysteine protease inhibitors, Ca074Me $(40 \mu \mathrm{M})$ and E64d $(10 \mu \mathrm{M})$, respectively. As seen in Figure 2B, reduced gelatinolytic activity (decreased green fluorescence) was observed at the pericellular region in the presence of the inhibitors. We additionally quantified by flow cytometry the effect of Ca074Me, E64d, and marimastat, an MMP inhibitor, on the intracellular degradation of DQ-gelatin and DQ-collagen I (Figure 2C). Similar to our results in porcine TM cells [12], degradation of DQ-substrates 
was significantly blocked by inhibiting CTSB (gelatin: $30.05 \pm 16 \%, p<0.01, n=3$; Col I: $58 \pm 17 \%, p<0.01, n=3$ ) and cysteine cathepsin activities (gelatin: $33 \pm 15 \%, p<0.05$, $n=3$; Col I: $67 \pm 19 \%, n=3$ ), at same levels of those observed with the MMP inhibitor (gelatin: $25 \pm 15 \%, p<0.01, n=3$; Col I: $58 \pm 16 \%, p<0.05, n=3$ ). Together, the results strongly confirm a role of CSTB and cysteine cathepsins in the pericellular and intracellular degradation of ECM components.

(A)

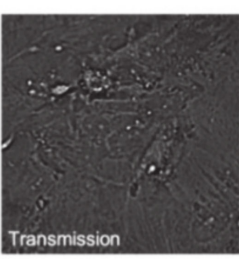

(B)

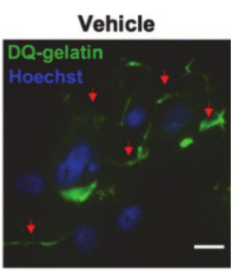

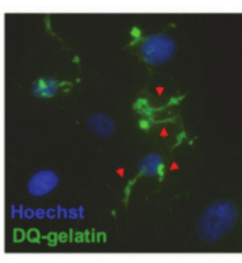

CA074Me $(40 \mu \mathrm{M})$

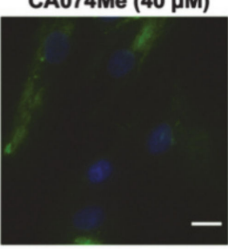

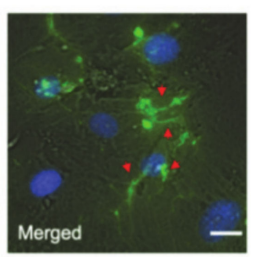

E64d (10 $\mu \mathrm{M})$

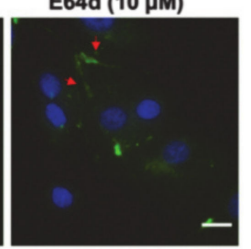

(C)

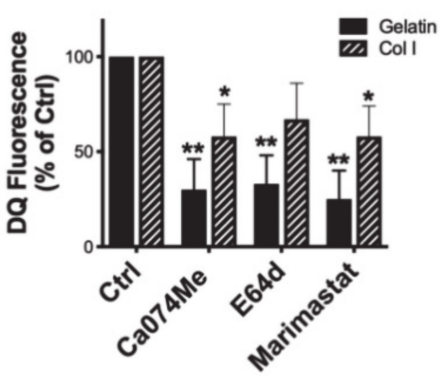

Figure 2. CTSB mediates pericellular proteolysis in hTM cells. (A) Representative image of pericellular proteolysis in hTM cells. Proteolytic degradation products of DQ-gelatin (green fluorescence) were monitored as described in materials and methods. (B) Representative image of pericellular proteolysis in hTM cells in the presence of the CTSB or cysteine cathepsin inhibitors Ca074Me and E64d, respectively. (C) Flow cytometry quantification of DQ-gelatin and DQ-Col I proteolytic degradation products in the presence and absence of Ca074Me, E64d, or marimastat (MMP inhibitor). Data are shown as the mean \pm S.D. ${ }^{*} p<0.05 ;{ }^{* *} p<0.01, n=3$. Hoechst (blue fluorescence) was used to stain nuclei. Red arrows represent the pericellular degradation of DQ-gelatin. Scale bars: $20 \mu \mathrm{m}$.

\subsection{Inhibition of CTSB Upregulates and Increases the Secretion of Plasminogen Activator Inhibitor 1 (PAI-1)}

Several studies have shown the ability of CTSB to degrade ECM either intracellularly, extracellularly, or both by initiating a proteolytic cascade that involves uPA, plasminogen (PLG), and PAI-1 [11,14,17,27-31]. We tested the effect of CTSB inhibition on the expression levels of the components of the proteolytic cascade PLG, uPA, and PAI-1 by WB. For this, we treated three independent primary cultures of human TM cells with Ca074, Ca074Me, or E64d for $24 \mathrm{~h}$. Intriguingly, inhibition of cysteine cathepsins or CTSB activity significantly increased the protein levels of PAI-1 (Figure 3A,B; Ca074Me: $250 \pm 27 \%, p=0.0007$; E64d: $242 \pm 58 \%, p=0.013$, $t$-test, $n=3$ ). No significant changes in the protein levels of PLG or UPA were observed (not shown). We additionally confirmed these results in human TM with silenced expression of CTSB. Cells were transfected with siRNA targeting CTSB (siCTSB) or control siRNA (siNC) for $72 \mathrm{~h}$ and treated with TGF $32(10 \mathrm{ng} / \mathrm{mL}, 48 \mathrm{~h})$. TGF $\beta 2$ is a known upregulator of PAI-1 and was used as a positive control. PAI-1 protein levels were evaluated by WB in whole cell lysates and conditioned media; mRNA PAI-1 levels were quantified by qPCR. As seen in Figure 3C-E, siCTSB knockdown significantly increased both intracellular and secreted protein levels of PAI-1. Higher PAI-1 mRNA levels were also observed in siCTSB-transfected cultures (Figure 3F). 
(A)

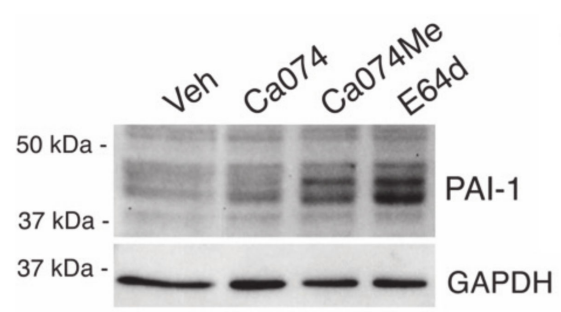

(C)

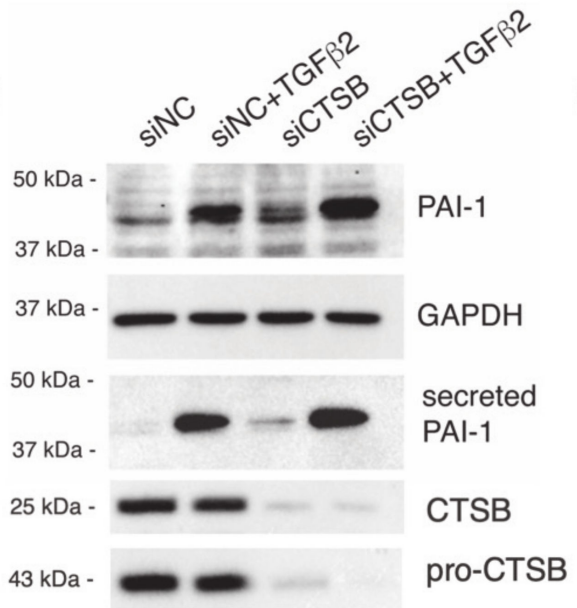

(E)

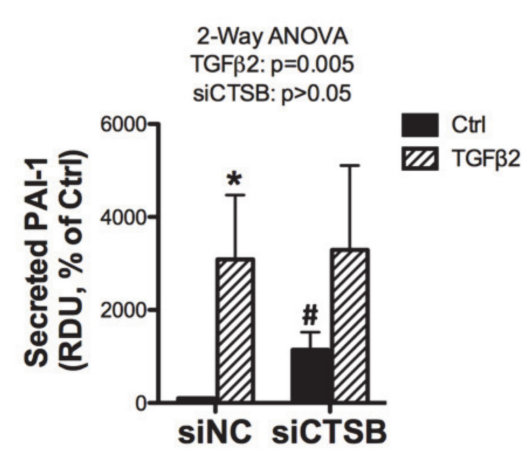

(B)

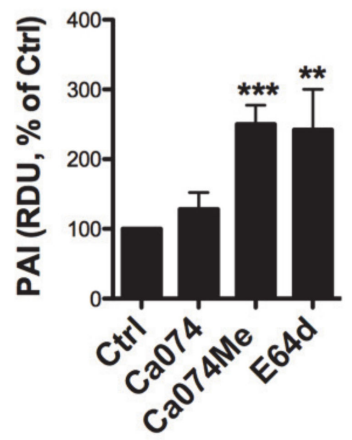

(D)

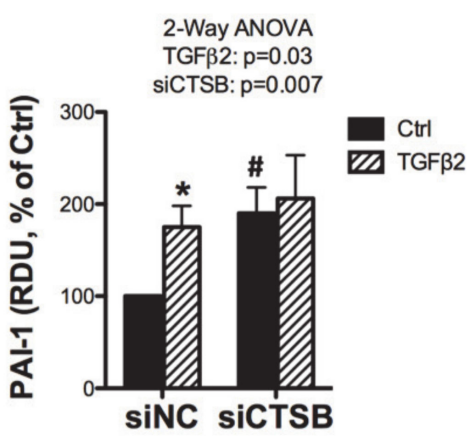

(F)

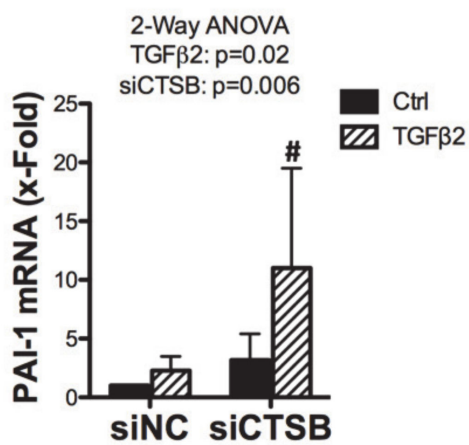

Figure 3. CTSB inhibition increases production and secretion of PAI-1. (A) Protein levels of PAI-1 evaluated by WB in whole cell lysates $(5 \mu \mathrm{g})$ from primary hTM cells treated with Ca074 $(40 \mu \mathrm{M})$, Ca074Me $(40 \mu \mathrm{M})$, and E64d $(10 \mu \mathrm{M})$ for $24 \mathrm{~h}$. Relative PAI-1 protein levels calculated from densitometric analysis of the bands are represented in (B). Data are shown as the mean \pm S.D. ${ }^{* *} p<0.01$; ${ }^{* * *} p<0.001, t$-test, $n=3$. (C) Protein levels of PAI-1 evaluated by WB in whole cell lysates ( $\left.5 \mu \mathrm{g}\right)$ and culture media $(15 \mu \mathrm{L})$ from primary hTM cells transfected for $72 \mathrm{~h}$ with siCTSB followed by TGF $\beta 2$ treatment $(10 \mathrm{ng} / \mathrm{mL}, 48 \mathrm{~h})$. Relative PAI-1 protein levels calculated from densitometric analysis of the bands are represented in $(\mathbf{D}, \mathbf{E})$. Data are shown as the mean \pm S.D. ${ }^{*} p<0.05$ 2-way ANOVA with Tukey comparison tests, $n=3$. (F) mRNA expression levels of PAI-1 in siCTSB-transfected TGF 32 -treated hTM cells calculated by qPCR. Data are shown as the mean \pm S.D. $p<0.052$-way ANOVA with Tukey comparison tests, $n=3 .{ }^{*}$ compares TGF $\beta 2$-treated to non-treated controls; \# compares siCTSB to siNC.

\subsection{CTSB Is Secreted into the Culture Media in Response to Cyclic Mechanical Stretch}

Cells in the TM are exposed to mechanical stretch due to continuous changes in IOP. It is well-known that TM cells sense and respond to those mechanical forces by eliciting a number of responses, among them ECM remodeling, which are believed to be directed at maintaining IOP homeostasis [32,33]. We wanted to check whether mechanical stretch could affect expression or secretion of CTSB. For this, we subjected three primary cultures 
of human TM cells to cyclic mechanical stress ( $8 \%$ elongation, $24 \mathrm{~h}$ ). CTSB expression was evaluated in whole cell lysates and culture media by WB. As seen in Figure $4 \mathrm{~A}$ and quantified in 4B, a decrease in intracellular CTSB (single- and double-chain forms) was found in the stretched cultures (sc-CTSB: $0.68 \pm 0.39$ folds; dc-CTSB: $0.39 \pm 0.34$ folds, $p<0.05, n=4$ ). In contrast, higher levels of CTSB (pro-CTSB) were observed in mechanically stretched cells.

(A)

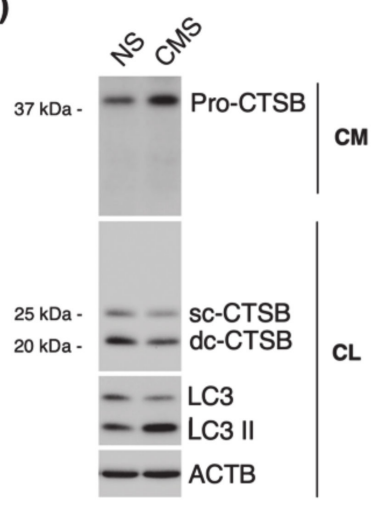

(B)

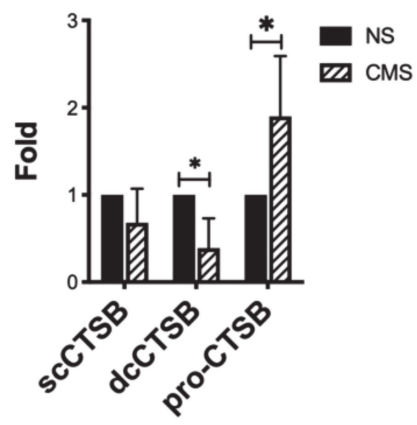

Figure 4. CTSB is secreted into the culture media in response to CMS. (A) Protein levels of CTSB in whole-cell lysates $(5 \mu \mathrm{g})$ and culture media $(15 \mu \mathrm{L})$ from hTM cells subjected to CMS ( $8 \%$ elongation, $24 \mathrm{~h}$ ), compared to non-stretched controls. (B) Relative quantification of pro-CTSB, sc-CTSB, and dcCTSB calculated from the densitometric analysis of the bands and compared to non-stretched controls. Data are shown as the mean \pm S.D. ${ }^{*} p<0.05$; two-tailed paired Student's $t$-test, $n=4$ and 5 for cell lysate and culture medium, respectively. NS: non-stretched; CMS: cyclic mechanical stretch; CM: culture media; CL: cell lysate. LC3 serves as control for mechanical stress.

\subsection{Downregulation of CTSB Decreases TGF $\beta 1$ and TGF $\beta 2$ and Modulates Smad2/3 Signaling} Pathway

Recent reports in the literature have implicated CTSB in TGF $\beta$ signaling and epithelialmesenchymal (EMT) transition [19,34,35]. Given the relevance of TGF $\beta$ and EMT in glaucoma pathogenesis, we investigated a potential regulatory effect of CTSB in these biological processes in TM cells. First, we quantified secreted levels of TGF $\beta 1$ and TGF $\beta 2$ in conditioned culture media from TM cells with silenced CTSB expression (siCTSB) via ELISA. Both TGF $\beta 1$ (Figure 5A, 55\% $\pm 20 \%, p=0.002$, $t$-test, $n=6$ ) and TGF $\beta 2$ (Figure 5B, 77\% \pm $5 \%, p<0.0001$, $t$-test, $n=4$ ) were significantly decreased in TM cells with downregulated CTSB. Phosphorylation of Smad2/3 in response to TGF $\beta$ treatment was evaluated by WB. As seen in Figure 5C and quantified in 5D, cells with silenced CTSB expression displayed higher levels of $\mathrm{p}-\mathrm{Smad} 2 / 3$ upon TGF $\beta 1$ (siCTSB: $2.656 \pm 0.478$ RDU vs. siNC: $1.292 \pm$ 0.394 RDU, $p<0.05, n=3$ ) or TGF $\beta 2$ (siCTSB: $2.458 \pm 0.367$ RDU vs. siNC: $1.358 \pm 0.545$ RDU, $p<0.05, n=3$ ) treatments, compared to siNC-transfected cells. We additionally analyzed expression of the downstream TGF $\beta /$ Smad signaling myofibroblast marker, smooth muscle actin (SMA). Higher levels of SMA with CTSB knockdown were observed in two out of the four hTM strains evaluated (Figure 5E, Supplementary Materials Figure S1). Intriguingly, in all the cell strains tested, inhibition of CTSB activity by Ca074Me resulted in a marked increase in SMA $(320 \pm 42 \%, p<0.0001, t$-test, $n=4)$. 
(A)

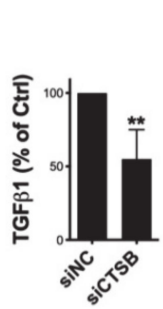

(B)

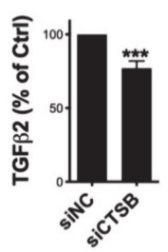

(E)

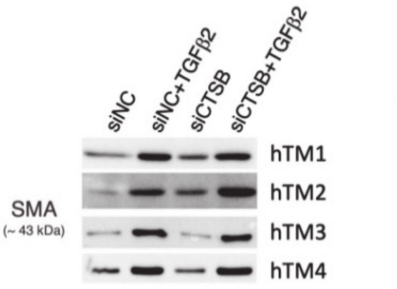

(C)

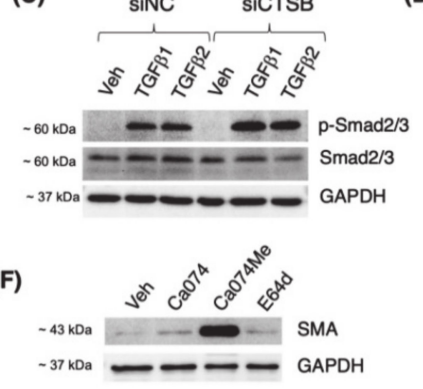

(D)

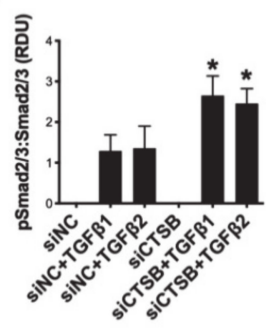

(G)

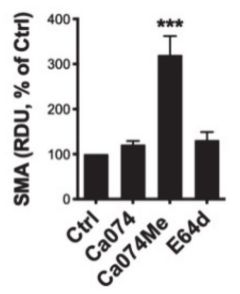

Figure 5. Effect of CTSB deficiency on TGF $\beta$ signaling. Secreted levels of (A) TGF $\beta 1$ and (B) TGF $\beta 2$ were quantified by ELISA in culture media from hTM primary cultures transfected with siCTSB or siNC control for $72 \mathrm{~h}$. Data are shown as the mean \pm S.D. ${ }^{* *}, p<0.01 ;{ }^{* *}, p<0.001, t$-test, $\mathrm{n}_{\mathrm{TGF} \beta 1}=6$, $\mathrm{n}_{\mathrm{TGF} \beta 2}=4$. (C) Protein levels of pSmad2/3 and Smad2/3 in whole-cell lysates $(5 \mu \mathrm{g})$ from hTM cells transfected with siCTSB or siNC for $72 \mathrm{~h}$ and subjected to TGF $\beta 1(10 \mathrm{ng} / \mathrm{mL})$ or TGF $\beta 2(10 \mathrm{ng} / \mathrm{mL})$ treatment for $48 \mathrm{~h}$. Relative pSmad2/3 protein levels calculated from densitometric analysis of the bands are represented in (D). Data are shown as the mean \pm S.D. ${ }^{*}, p<0.05$ ANOVA with Tukey comparison tests, $n=3$. (E) Protein levels of SMA in whole-cell lysates $(5 \mu \mathrm{g})$ from four independent hTM strains transfected with siCTSB or siNC for $72 \mathrm{~h}$ and subjected to TGF $\beta 2(10 \mathrm{ng} / \mathrm{mL})$ or TGF $\beta 2$ $(10 \mathrm{ng} / \mathrm{mL})$ treatment for $48 \mathrm{~h}$. (F) Protein levels of SMA in whole-cell lysates $(5 \mu \mathrm{g})$ from hTM cells treated with Ca074 $(40 \mu \mathrm{M})$, Ca074Me $(40 \mu \mathrm{M})$, or E64d $(10 \mu \mathrm{M})$ for $24 \mathrm{~h}$. Relative SMA protein levels calculated from densitometric analysis of the bands are represented in $(\mathbf{G})$. Data are shown as the mean \pm S.D. ${ }^{* * *}, p<0.001, t$-test, $n=4$.

\subsection{CTSB Knockout Mice Display Defective uPA Activation in the Iridocorneal Region}

Next, we investigated the potential effects of CTSB deficiency in outflow pathway tissue physiology. For this, we monitored IOP and outflow facility in CTSB deficient mice $\left(\right.$ CSTB $\left.^{\mathrm{ko}}\right)$ and littermate CTSB mice. As seen in Figure 6A, no difference in IOP was observed between CTSB and $\mathrm{CTSB}^{\mathrm{ko}}$ mice, evaluated up to 18-month-old age. Interestingly, an increased in outflow facility was observed in CTSB ${ }^{\mathrm{ko}}$ mice compared to CTSB control, although it did not reach statistical significance (Figure 6B, CTSB ${ }^{\mathrm{ko}}: 5.155$ $\pm 1.836 \mathrm{nl} / \mathrm{min} / \mathrm{mmHg}$ vs. CTSB: $4.03 \pm 0.739 \mathrm{~nL} / \mathrm{min} / \mathrm{mmHg}, p=0.07, t$-test, $n=10$ ). Based on the findings in our in vitro studies, we analyzed the expression levels of several components of the proteolytic cascade in dissected iridocorneal region tissues of CTSB ${ }^{\mathrm{ko}}$ and littermates CTSB, based on antibody availability (Figure 6C, D). Absence of CSTB in the iridocorneal region tissue in $\mathrm{CTSB}^{\mathrm{ko}}$ mice was confirmed. Compared to CTSB, CTSB ${ }^{\mathrm{ko}}$ mice displayed a very significant increase in pro-uPA $\left(\mathrm{CTSB}^{\mathrm{ko}}: 1.850 \pm 0.178\right.$ RDU vs. CTSB: $0.735 \pm 0.494$ RDU; $p=0.005, t$-test, $n=4)$. This was accompanied by a decrease in uPA-PAI-1 levels (CTSB ${ }^{\mathrm{ko}}$ : $0.248 \pm 0.167$ RDU vs. CTSB: $0.610 \pm 0.198$ RDU; $p=0.006, t$-test, $n=6)$. Decreased levels of cystatin C (CSTC), an endogenous CTSB inhibitor, were also found in $\mathrm{KO}$ mice (CTSB ${ }^{\mathrm{k} o}: 0.525 \pm 0.215$ RDU vs. CTSB: $0.838 \pm 0.279$ RDU; $p=0.04$, $t$-test, $\left.\mathrm{n}_{\mathrm{CTSB}}=7, \mathrm{n}_{\mathrm{CTSB}}=6\right)$. Additionally, $\mathrm{CTSB}^{\mathrm{ko}}$ mice displayed higher levels of the fibrotic marker SMA (CTSB ${ }^{\mathrm{ko}}: 1.255 \pm 0.398$ RDU vs. CTSB: $0.738 \pm 0.229$ RDU; $p=0.016$, t-test, $\mathrm{n}_{\mathrm{CTSB}}=7, \mathrm{n}_{\mathrm{CTSBko}}=6$ ), but no significant changes in fibronectin (FN1) were detected. 
(A)

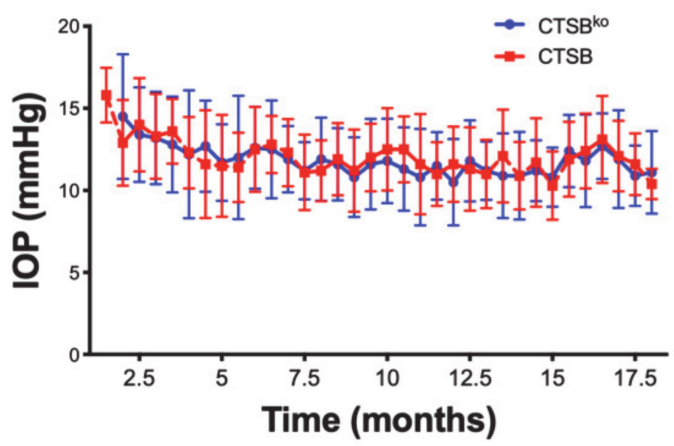

(B)

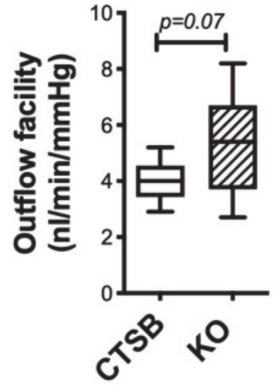

(C)

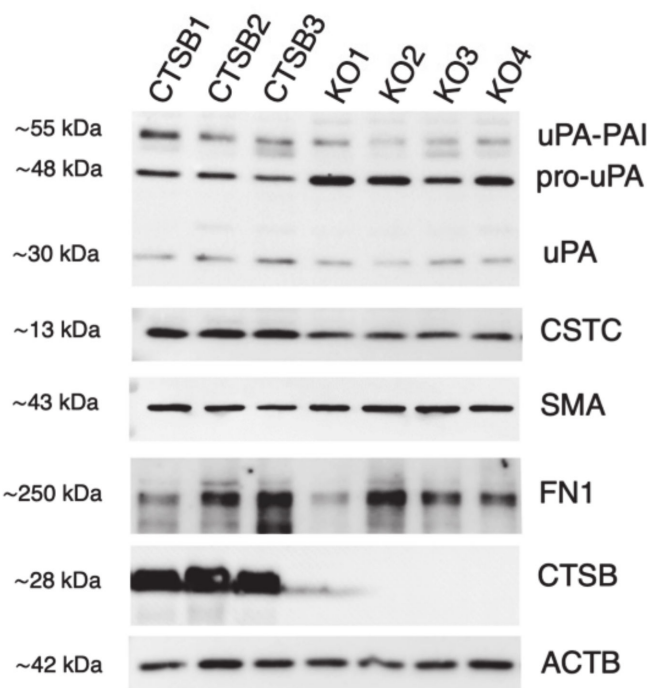

(D)
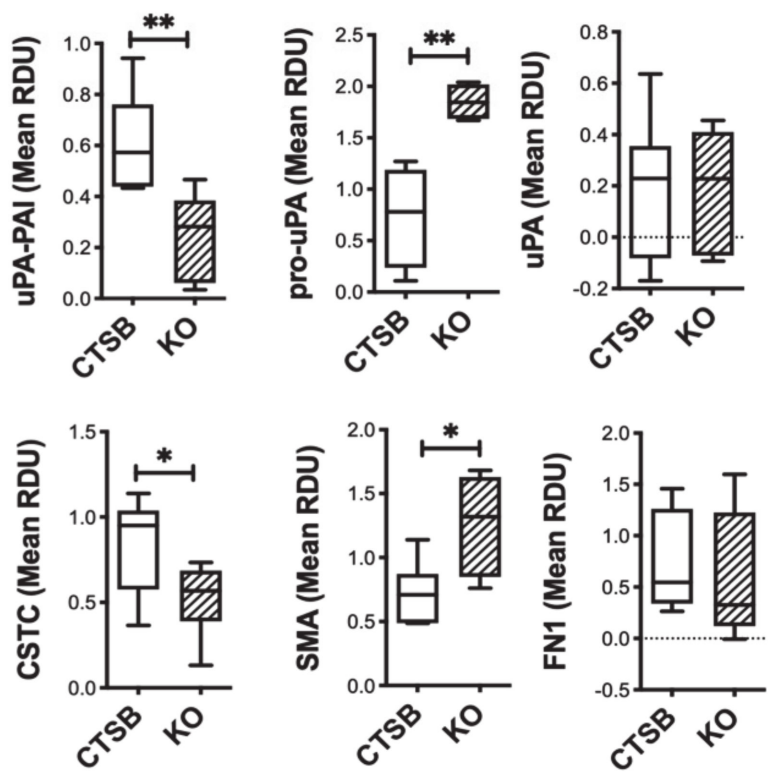

Figure 6. Effect of CTSB deficiency in outflow pathway physiology and morphology. (A) Mean IOP (mm $\mathrm{Hg}$ ) over time in $\mathrm{CTSB}^{\mathrm{ko}}$ and CTSB mice. Data are shown as the mean \pm S.D., $n=20$. (B) Mean outflow facility in CTSB ${ }^{\mathrm{ko}}$ and CTSB mice (4 m.o.) evaluated ex-vivo with the iPerfusion system. Data are shown as the mean \pm S.D., $\mathrm{n}_{\text {CTSB }}=10, \mathrm{n}_{\text {CTSBko }}=11$. (C) Protein levels of uPA (uPA/PAI, pro-uPA, uPA), CTSC, SMA, FN1, and CSTB evaluated by WB in whole cell lysates $(5 \mu \mathrm{g})$ from primary hTM cells. Relative protein levels were calculated from densitometric analysis of the bands and represented in (D). Data are shown as the mean \pm S.D. ${ }^{*} p<0.05,{ }^{* *} p<0.01 ; t$-test, $n=4-7$.

EM morphometric analysis showed no gross changes in outflow pathway morphology in CTSB ${ }^{\mathrm{ko}}$ mice (Figure 7). Both cells and ECM look normal in the TM of KO mice compared to CTSB mouse eyes; no obvious differences were observed in either the endothelial cell of Schlemm's canal, juxtacanalicular connective tissue regions, or TM endothelial lining cells between the two groups. 

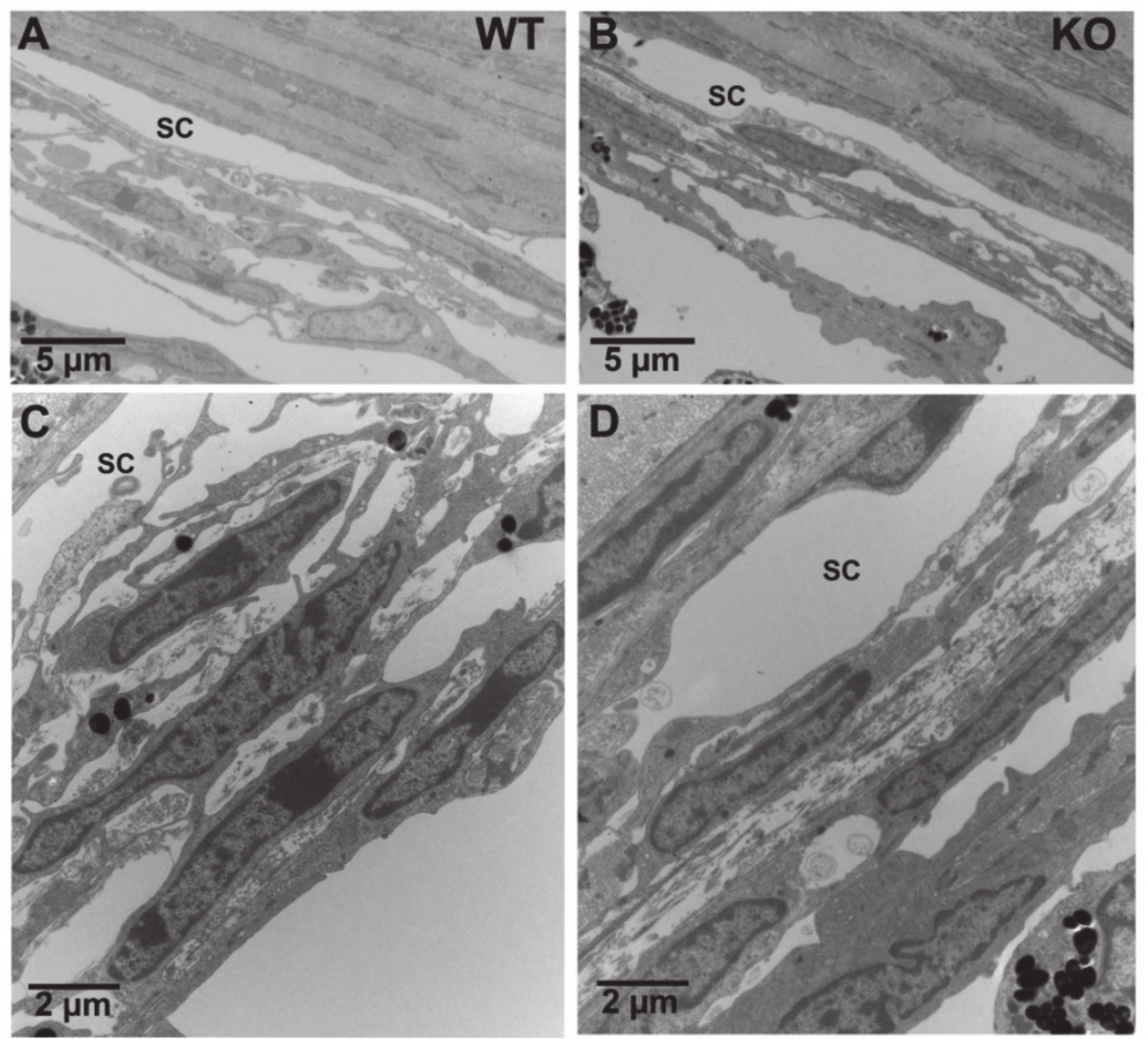

Figure 7. Morphological Comparison of Trabecular Meshwork between CTSB and CTSB ${ }^{\mathrm{ko}}$ mouse eyes. (A-C): Representative electron microscopy images of the TM from CTSB mouse eyes at lower (A) and higher (C) magnifications. (B-D): Representative electron microscopy images of the TM from $\mathrm{CTSB}^{\mathrm{ko}}$ mouse eyes at lower (B) and higher (D) magnifications. Compared to CTSB mouse eyes, no obvious differences were observed in the endothelial cell of Schlemm's canal (SC), cells and extracellular matrix in the juxtacanalicular connective tissue regions, and the endothelial cells and extracellular matrix core of trabecular beams in CTSB ${ }^{\mathrm{ko}}$ mouse eyes.

\section{Discussion}

In this manuscript, we report for the first time that CTSB localizes in the caveolae and participates in the pericellular degradation of ECM in TM cells. We also report here a novel role of CTSB in regulating the expression of PAI- 1 and TGF $\beta /$ Smad signaling in vitro and in vivo in $\mathrm{CTSB}^{\mathrm{ko}}$ mice.

Caveolae are unique invaginated lipid-rich regions of the plasma membrane highly abundant in mechanically stretched cells that play a major role in regulating cell signaling, lipid homeostasis, and adaptation to membrane tension. Although less investigated, emerging studies are showing that caveolae are important regulators of ECM remodeling, acting as focal proteolytic degradation sites. Disruption of caveolae formation in Cav1-deficient cells results in abnormal expression of matrix proteins [36-38]. In TM cells, Cav1 deficiency has been shown to alter the physiological catabolism of ECM and modulate outflow resistance [39]. First, many proteases implicated in ECM remodeling are associated or localized to the caveolae. Second, caveolae mediates internalization, via endocytosis, of partially degraded ECM fragments and targets them for final degradation within lysosomes. Along these lines, our studies revealed the localization of members of the proteolytic cascade, pro-uPA and UPAR, along with that of the cysteine cathepsin CTSB in Cav-1-enriched fractions from TM cells. Interestingly, AnxA2, a reported cell surface receptor for tPA and CTSB was also localized in the caveolae [28]. CTSB in the caveolae was found in its 
inactive (pro-CTSB) and as a single chain (sc-CTSB) forms, consistent with the notion that sc- to dc- maturation occurs in lysosomes. An advantage of localization of CTSB in the caveolae is the quick availability. Our results showed increased secretion of pro-CTSB in response of mechanical stretch. It is plausible that mechanical deformation of caveolae with mechanical forces triggers the release of the pro-enzyme and be one of the contributing factors initiating ECM remodeling in stretched cells.

Using a live-cell proteolysis assay in combination with CTSB inhibitors, we confirmed the contribution of cell surface CTSB in the pericellular degradation of ECM components. ECM degradation at the cell surface occurs by the coordinated action of different types of proteases and their receptors. In a proposed model for tumor cells, activation of receptorbound-pro-CTSB (AnxA2/CTSB) at the caveolae triggers the uPA/plasminogen/plasmin proteolytic cascade that culminates with MMP activation and ECM breakdown. CTSB can also directly activate some MMPs. Very interestingly, pharmacological inhibition or silencing of CTSB resulted in transcriptional upregulation and increased secretion of PAI-1 in TM cells. PAI- 1 is a member of the superfamily of serine-protease inhibitors or serpins and potent inhibitor or tPA and UPA. PAI-1 binds to uPA/uPAR complex and targets uPAR for degradation. To our knowledge, this is the first time that regulation of PAI-1 expression by CTSB is reported and adds a novel mechanism by which CTSB can modulate ECM proteolysis in addition to proteolytic activation. Consistent with these results, we observed increased levels of pro-uPA in the dissected iridocorneal mouse tissue of $\mathrm{CTSB}^{\mathrm{ko}}$ mice compared to CTSB controls. CTSB ${ }^{\mathrm{ko}}$ mice also displayed lower levels of CTSC, an endogenous inhibitor for CTSB, suggesting a regulatory feedback between the two proteins.

Noteworthy are the increased levels of SMA in the iridocorneal region of CTSB ${ }^{\mathrm{ko}}$ mice. A marked increase in SMA protein levels was also identified in vitro in hTM cells treated with the CTSB inhibitor Ca074Me. One could argue that the observed increase in pSmad2/3 levels could explain the increase in SMA. However, silencing CTSB expression elevated SMA levels in just two out of the four cell strains tested, while elevated pSmad2/3 was observed in all of them. Intriguingly, the capability of CTSB to modulate SMA seems to be a cell strain-intrinsic factor, since independently conducted replicate experiments using the same cell strains yield the same outcomes. It is plausible that elevated SMA levels might also result from defective CTSB-mediated degradation of either SM or SMA negative transactivation signal. That might partially explain the why irreversible inactivation of CTSB activity with Ca074Me resulted in such remarkable increase in SMA protein levels. This, however, requires further investigation.

A role of CTSB in EMT and tissue fibrosis has been investigated in a very recent work [34]. In this elegant study, Zhang et al. report a differential role of cysteine cathepsins in TGF $\beta$ signaling and kidney fibrosis. Interestingly, using a model of unilateral ureteral obstruction, the authors found that CTSB or CTSL deficiency in mice exacerbates kidney fibrosis, whereas CTSS or CTSK deficiency protects it. Similar to our own results, they detected higher expression levels of SMA in CTSB ${ }^{\mathrm{ko}}$ mice. More, also as in siCTSB-transfected TM cells, tubular epithelial cells deficient in CTSB showed increased pSmad2/3 in response to TGF $\beta$ treatment. Intriguingly, they found that this resulted from the interaction of membrane surface CTSB with TGFBR1, targeting TGFBR1 for degradation and abolishing downstream TGF $\beta$ signaling. CTSB has been also shown to regulate TGF $\beta$ pathway by participating in the intracellular proteolytic activation and maturation of TGF $\beta 1$ [35]. Although not confirmed in TM cells, this could certainly explain the observed lower secreted levels of TGF $\beta 1$ and TGF $\beta 2$ in siCTSB-transfected TM cells.

Fibrosis and EMT transition have been linked to the pathogenesis of glaucoma. The fact that despite the increase in SMA and diminished pro-UPA activation CTSB ${ }^{\mathrm{ko}}$ mice showed a trend in higher-than rather lower-outflow facility and no significant morphological or physiological changes in the outflow pathway tissues was somehow a little disappointing and unexpected. As we previously reported, glaucomatous TM cells display lower CTSB protein levels [40]. Several contributing factors can explain these results. First and foremost is the known compensatory role of cysteines cathepsins, in par- 
ticular between CTSB and CTSL [41]. The second factor is age. While no differences in IOP were noted over time, outflow facilities and morphological analysis were conducted just in young mice. The third factor is TGF $\beta$. As indicated by our results presented here and those in [34] [35], there is a complex relationship between CTSB and TGF $\beta$ signaling. While decreased levels of TGF $\beta 1$ and TGF $\beta 2$ were noted in TM cells with knockdown expression of CTSB, the concentration of TGF $\beta 2$ in AH from glaucomatous eyes is known to be higher than that in age-matched control eyes. It is therefore expected that effects of CTSB differ in a physiological compared to a pro-fibrotic environment. Future experiments will be directed at exploring the effect of aging and pro-fibrotic environment in CTSB-mediated activation of the proteolytic cascade and ECM remodeling.

\section{Conclusions}

In summary, we have identified here CTSB as a novel mechanosensitive player regulator of the proteolytic cascade and TGF $\beta$ signaling in TM cells. Small drugs targeting cathepsins are currently being developed and tested in clinical trials to treat diseases with imbalance ECM turnover. Similar approaches targeted at enhancing CTSB activity or restoring CTSB levels in the glaucomatous TM could be developed to attenuate fibrosis and ECM deposition in the TM in glaucoma.

Supplementary Materials: The following are available online at https:/ / www.mdpi.com/2077-038 3/10/1/78/s1, Figure S1: Effect of CTSB deficiency on SMA. Protein levels of SMA in whole-cell lysates $(5 \mu \mathrm{g})$ from four independent hTM strains transfected with siCTSB or siNC for $72 \mathrm{~h}$ and subjected to TGF $\beta 2(10 \mathrm{ng} / \mathrm{mL})$ or TGF $\beta 2(10 \mathrm{ng} / \mathrm{mL})$ treatment for $48 \mathrm{~h}$. Graph represents relative protein levels calculated from densitometric analysis of the bands.

Author Contributions: A.N. and M.S.S. designed, performed, and analyzed the experiments. A.D. and U.R. assisted in the in vivo experiments. H.G. conducted the EM analysis; P.B.L. conceived the original idea and directed experiments and planning. A.N., M.S.S., and P.B.L. analyzed the data and wrote the manuscript. All authors have read and agreed to the published version of the manuscript.

Funding: This research was funded by National Institute of Health, Eye Institute [EY026885, EY027733, EY005722], and Unrestricted Research to Prevent Blindness Grant.

Institutional Review Board Statement: The protocols involving the use of human tissue were approved under the Duke University Institutional Review Board (protocol \#00050810) and were consistent with the tenets of the Declaration of Helsinki. All procedures involving vertebrate animals were reviewed and approved by the Institutional Animal Care and Use Committee of Duke University and were performed in accordance with the Association for Research in Vision and Ophthalmology Statement for the Use of Animals in Ophthalmic and Vision Research and the National Institutes of Health Guide for the Care and Use of Laboratory Animals.

Informed Consent Statement: Informed consent was obtained by BioSight (Duke University School of Medicine Service Center and Repository) from all subjects involved in the study.

Acknowledgments: We would like to thank Henriette Van Praag at Florida Atlantic University (FL, USA) for kindly providing CTSB ${ }^{\mathrm{ko}}$ mice.

Conflicts of Interest: The authors declare no conflict of interest.

\section{References}

1. Bill, A.; Phillips, C.I. Uveoscleral drainage of aqueous humour in human eyes. Exp. Eye Res. 1971, 12, 275-281. [CrossRef]

2. Quigley, H.A. Glaucoma. Lancet 2011, 377, 1367-1377. [CrossRef]

3. Rohen, J.W.; Lütjen-Drecoll, E.; Flügel, C.; Meyer, M.; Grierson, I. Ultrastructure of the trabecular meshwork in untreated cases of primary open-angle glaucoma (POAG). Exp. Eye Res. 1993, 56, 683-692. [CrossRef] [PubMed]

4. Acott, T.S.; Kelley, M.J. Extracellular matrix in the trabecular meshwork. Exp. Eye Res. 2008, 86, 543-561. [CrossRef] [PubMed]

5. Ochiai, Y.; Ochiai, H. Higher concentration of transforming growth factor-beta in aqueous humor of glaucomatous eyes and diabetic eyes. Jpn. J. Ophthalmol. 2002, 46, 249-253. [CrossRef]

6. Shepard, A.R.; Millar, J.C.; Pang, I.-H.; Jacobson, N.; Wang, W.-H.; Clark, A.F. Adenoviral gene transfer of active human transforming growth factor-\{beta\}2 elevates intraocular pressure and reduces outflow facility in rodent eyes. Investig. Ophthalmol. Vis. Sci. 2010, 51, 2067-2076. [CrossRef] 
7. Junglas, B.; Kuespert, S.; Seleem, A.A.; Struller, T.; Ullmann, S.; Bösl, M.; Bosserhoff, A.; Köstler, J.; Wagner, R.; Tamm, E.R.; et al. Connective tissue growth factor causes glaucoma by modifying the actin cytoskeleton of the trabecular meshwork. Am. J. Pathol. 2012, 180, 2386-2403. [CrossRef] [PubMed]

8. Bradley, J.M.; Vranka, J.; Colvis, C.M.; Conger, D.M.; Alexander, J.P.; Fisk, A.S.; Samples, J.R.; Acott, T.S. Effect of matrix metalloproteinases activity on outflow in perfused human organ culture. Investig. Ophthalmol. Vis. Sci. 1998, 39, $2649-2658$.

9. Spiga, M.-G.; Borrás, T. Development of a gene therapy virus with a glucocorticoid-inducible MMP1 for the treatment of steroid glaucoma. Investig. Ophthalmol. Vis. Sci. 2010, 51, 3029-3041. [CrossRef]

10. Stamer, W.D.; Acott, T.S. Current understanding of conventional outflow dysfunction in glaucoma. Curr. Opin. Ophthalmol. 2012, 23, 135-143. [CrossRef]

11. Broemme, D.; Wilson, S. Role of Cysteine Cathepsins in Extracellular Proteolysis. In The Extracellular Matrix: An Overview, 1st ed.; Parks, W.C., Mecham, R.P., Eds.; Springer: Berlin/Heidelberg, Germany, 2011; pp. 23-51.

12. Porter, K.; Lin, Y.; Liton, P.B. Cathepsin B is up-regulated and mediates extracellular matrix degradation in trabecular meshwork cells following phagocytic challenge. PLoS ONE 2013, 8, e68668. [CrossRef] [PubMed]

13. Brix, K.; Dunkhorst, A.; Mayer, K.; Jordans, S. Cysteine cathepsins: Cellular roadmap to different functions. Biochimie 2008, 90, 194-207. [CrossRef] [PubMed]

14. Vreemann, A.; Qu, H.; Mayer, K.; Andersen, L.B.; Stefana, M.I.; Wehner, S.; Lysson, M.; Farcas, A.M.; Peters, C.; Reinheckel, T.; et al. Cathepsin B release from rodent intestine mucosa due to mechanical injury results in extracellular matrix damage in early post-traumatic phases. Biol. Chem. 2009, 390, 481-492. [CrossRef] [PubMed]

15. Jane, D.T.; Morvay, L.; Dasilva, L.; Cavallo-Medved, D.; Sloane, B.F.; Dufresne, M.J. Cathepsin B localizes to plasma membrane caveolae of differentiating myoblasts and is secreted in an active form at physiological pH. Biol. Chem. 2006, 387, 223-234. [CrossRef] [PubMed]

16. Cavallo-Medved, D.; Dosescu, J.; Linebaugh, B.E.; Sameni, M.; Rudy, D.; Sloane, B.F. Mutant K-ras regulates cathepsin B localization on the surface of human colorectal carcinoma cells. Neoplasia 2003, 5, 507-519. [CrossRef]

17. Cavallo-Medved, D.; Rudy, D.; Blum, G.; Bogyo, M.; Caglic, D.; Sloane, B.F. Live-cell imaging demonstrates extracellular matrix degradation in association with active cathepsin B in caveolae of endothelial cells during tube formation. Exp. Cell Res. 2009, 315, 1234-1246. [CrossRef] [PubMed]

18. Cavallo-Medved, D.; Mai, J.; Dosescu, J.; Sameni, M.; Sloane, B.F. Caveolin-1 mediates the expression and localization of cathepsin, B.; pro-urokinase plasminogen activator and their cell-surface receptors in human colorectal carcinoma cells. J. Cell Sci. 2005, 118, 1493-1503. [CrossRef]

19. Mitrović, A.; Pečar Fonović, U.; Kos, J. Cysteine cathepsins B and X promote epithelial-mesenchymal transition of tumor cells. Eur. J. Cell Biol. 2017, 96, 622-631. [CrossRef]

20. Nettesheim, A.; Shim, M.S.; Hirt, J.; Liton, P.B. Transcriptome analysis reveals autophagy as regulator of TGF $\beta /$ Smad-induced fibrogenesis in trabecular meshwork cells. Sci. Rep. 2019, 9, 16092. [CrossRef]

21. Keller, K.E.; Bhattacharya, S.K.; Borrás, T.; Brunner, T.M.; Chansangpetch, S.; Clark, A.F.; Dismuke, W.M.; Du, Y.; Elliott, M.H.; Ethier, C.R.; et al. Consensus recommendations for trabecular meshwork cell isolation, characterization and culture. Exp. Eye Res. 2018, 171, 164-173. [CrossRef]

22. Shim, M.S.; Nettesheim, A.; Hirt, J.; Liton, P.B. The Autophagic Protein LC3 Translocates to the Nucleus and Localizes in the Nucleolus Associated to NUFIP1 in Response to Cyclic Mechanical Stress. Autophagy; Taylor \& Francis: Abingdon, UK, 2019; Volume 40, pp. 1-14. [CrossRef]

23. Moon, H.Y.; Becke, A.; Berron, D.; Becker, B.; Sah, N.; Benoni, G.; Janke, E.; Lubejko, S.T.; Greig, N.H.; Mattison, J.A.; et al. Running-Induced Systemic Cathepsin B Secretion Is Associated with Memory Function. Cell Metab. 2016, 24, 332-340. [CrossRef] [PubMed]

24. Deussing, J.; Roth, W.; Saftig, P.; Peters, C.; Ploegh, H.L.; Villadangos, J.A. Cathepsins B and D are dispensable for major histocompatibility complex class II-mediated antigen presentation. Proc. Natl. Acad. Sci. USA 1998, 95, 4516-4521. [CrossRef] [PubMed]

25. Sherwood, J.M.; Reina-Torres, E.; Bertrand, J.A.; Rowe, B.; Overby, D.R. Measurement of Outflow Facility Using iPerfusion. PLoS ONE 2016, 11, e0150694. [CrossRef] [PubMed]

26. Jia, J.-Y.; Lamer, S.; Schümann, M.; Schmidt, M.R.; Krause, E.; Haucke, V. Quantitative proteomics analysis of detergent-resistant membranes from chemical synapses: Evidence for cholesterol as spatial organizer of synaptic vesicle cycling. Mol. Cell. Proteom. 2006, 5, 2060-2071. [CrossRef]

27. Obermajer, N.; Jevnikar, Z.; Doljak, B.; Kos, J. Role of cysteine cathepsins in matrix degradation and cell signalling. Connect. Tissue Res. 2008, 49, 193-196. [CrossRef]

28. Sloane, B.F.; Yan, S.; Podgorski, I.; Linebaugh, B.E.; Cher, M.L.; Mai, J.; Cavallo-Medved, D.; Sameni, M.; Dosescu, J.; Moin, K. Cathepsin B and tumor proteolysis: Contribution of the tumor microenvironment. Semin. Cancer Biol. 2005, 15, 149-157. [CrossRef]

29. Sameni, M.; Moin, K.; Sloane, B.F. Imaging proteolysis by living human breast cancer cells. Neoplasia 2000, 2, 496-504. [CrossRef]

30. Tu, C.; Ortega-Cava, C.F.; Chen, G.; Fernandes, N.D.; Cavallo-Medved, D.; Sloane, B.F.; Band, V.; Band, H. Lysosomal cathepsin B participates in the podosome-mediated extracellular matrix degradation and invasion via secreted lysosomes in v-Src fibroblasts. Cancer Res. 2008, 68, 9147-9156. [CrossRef] 
31. Kobayashi, H.; Moniwa, N.; Sugimura, M.; Shinohara, H.; Ohi, H.; Terao, T. Effects of membrane-associated cathepsin B on the activation of receptor-bound prourokinase and subsequent invasion of reconstituted basement membranes. Biochim. Biophys. Acta (BBA)-Mol. Cell Res. 1993, 1178, 55-62. [CrossRef]

32. WuDunn, D. Mechanobiology of trabecular meshwork cells. Exp. Eye Res. 2009, 88, 718-723. [CrossRef]

33. Liton, P.B.; Gonzalez, P. Stress response of the trabecular meshwork. J. Glaucoma 2008, 17, 378-385. [CrossRef] [PubMed]

34. Zhang, X.; Zhou, Y.; Yu, X.; Huang, Q.; Fang, W.; Li, J.; Bonventre, J.V.; Sukhova, G.K.; Libby, P.; Shi, G.P. Differential Roles of Cysteinyl Cathepsins in TGF- $\beta$ Signaling and Tissue Fibrosis. IScience 2019, 19, 607-622. [CrossRef] [PubMed]

35. Kasabova, M.; Joulin-Giet, A.; Lecaille, F.; Gilmore, B.F.; Marchand-Adam, S.; Saidi, A.; Lalmanach, G. Regulation of TGF- $\beta 1-$ Driven Differentiation of Human Lung Fibroblasts: Emerging Roles of Cathepsin B and Cystatin, C. J. Biol. Chem. 2014, 289, 16239-16251. [CrossRef] [PubMed]

36. Thompson, C.; Rahim, S.; Arnold, J.; Hielscher, A. Loss of caveolin-1 alters extracellular matrix protein expression and ductal architecture in murine mammary glands. PLoS ONE 2017, 12, e0172067. [CrossRef]

37. Goetz, J.G.; Minguet, S.; Navarro-Lérida, I.; Lazcano, J.J.; Samaniego, R.; Calvo, E.; Tello, M.; Osteso-Ibáñez, T.; Pellinen, T.; Echarri, A.; et al. Biomechanical remodeling of the microenvironment by stromal caveolin-1 favors tumor invasion and metastasis. Cell 2011, 146, 148-163. [CrossRef]

38. Yamaguchi, Y.; Yasuoka, H.; Stolz, D.B.; Feghali-Bostwick, C.A. Decreased caveolin-1 levels contribute to fibrosis and deposition of extracellular IGFBP-5. J. Cell. Mol. Med. 2011, 15, 957-969. [CrossRef]

39. Aga, M.; Bradley, J.M.; Wanchu, R.; Yang, Y.-F.; Acott, T.S.; Keller, K.E. Differential effects of caveolin-1 and -2 knockdown on aqueous outflow and altered extracellular matrix turnover in caveolin-silenced trabecular meshwork cells. Investig. Ophthalmol. Vis. Sci. 2014, 55, 5497-5509. [CrossRef]

40. Porter, K.; Hirt, J.; Stamer, W.D.; Liton, P.B. Autophagic dysregulation in glaucomatous trabecular meshwork cells. Biochim. Biophys. Acta (BBA)-Mol. Basis Dis. 2015, 1852, 379-385. [CrossRef]

41. Tholen, S.; Biniossek, M.L.; Gansz, M.; Ahrens, T.D.; Schlimpert, M.; Kizhakkedathu, J.N.; Reinheckel, T.; Schilling, O. Double deficiency of cathepsins $\mathrm{B}$ and $\mathrm{L}$ results in massive secretome alterations and suggests a degradative cathepsin-MMP axis. Cell. Mol. Life Sci. 2014, 71, 899-916. [CrossRef] 